\title{
Letter From the Editor-in-Chief: Journal Transition in the Digital Age
}

\author{
M. Maral Mouradian ${ }^{1}$
}

Published online: 10 October 2017

(C) The American Society for Experimental Neurotherapeutics, Inc. 2017

This October 2017 issue of Neurotherapeutics marks the final issue of the Journal that will be published in print. The time has come for the official journal of the American Society for Experimental Neurotherapeutics to be available online only. This transition reflects a larger trend in $21^{\text {st }}$ century scientific publishing and, indeed, scholarship as a whole. The digital evolution has made the internet the primary vehicle for disseminating information, including scientific knowledge.

The benefits of online-only publishing are clear. In addition to reducing the carbon footprint of printing and mailing the hard copy journal, online access makes content readily accessible worldwide, with enhanced usability through fullreference linking, quick word searching, and article sharing.

Online articles will continue being available as fully formatted PDFs as readers have come to expect from traditional print publishing. And the journal will continue its tradition of having no page limitations, page charges or color charges for its authors.

The editorial process remains the same. Each issue comprises a set of invited thematic critical reviews of broad interest on current and emerging treatments of neurologic disorders, provides a platform for publishing points of view by key opinion leaders, as well as unsolicited original translational research articles. Peer review continues being fair, constructive, rigorous and efficient.

The Journal will continue being published by Springer Nature. Readers are encouraged to sign up for table of contents alerts at http://www.springer.com/biomed/ neuroscience/journal/13311.

January 2018 marks another transition for Neurotherapeutics as we welcome Raymond A. Swanson, MD, of the University of California, San Francisco, as our new Associate Editor. Ray replaces Rajiv R. Ratan, MD, $\mathrm{PhD}$, who will step down from this position after four years of exemplary service to pursue his many other interests. Gregory K. Bergey, MD, continues as Associate Editor. The able support of the Editorial Manager, Linda Powell, ensures that the day-to-day operations of the editorial office run smoothly and efficiently. Our Editorial Board members and peer reviewers are essential for maintaining the highest quality of publication. The ongoing effective collaboration with the staff at Springer Nature has made this transition to online-only publishing possible, and we look forward to this new chapter for Neurotherapeutics.

M. Maral Mouradian, MD

Editor-in-Chief

Required Author Forms Disclosure form provided by the author is available with the online version of this article.

Electronic supplementary material The online version of this article (https://doi.org/10.1007/s13311-017-0578-z) contains supplementary material, which is available to authorized users.

M. Maral Mouradian

m.mouradian@ rutgers.edu

1 Rutgers - Robert Wood Johnson Medical School, Piscataway, NJ 08854, USA 